\title{
Avaliação de desempenho das atividades em um Centro Cirúrgico
}

\author{
Aline Narcizo Gomes*, Ana Paula Boaventura
}

\section{Resumo}

O objetivo deste projeto foi caracterizar e avaliar o perfil das cirurgias realizadas no Centro Cirúrgico de um hospital universitário por um período de cinco anos. Trata-se de um estudo quantitativo e descritivo cujas variáveis obtidas e analisadas foram sexo, faixa etária, local, tipo de anestesia, procedimento cirúrgico, especialidade cirúrgica e desfecho. Foram realizadas 39.471 cirurgias em cinco anos, sendo a maioria em pacientes do sexo masculino $(57,83 \%)$, sendo os principais procedimentos cirúrgicos as correções de fraturas e luxações $(6,93 \%)$ seguido de laparotomia exploratória $(4,01 \%)$. Observou-se na preparação um tempo médio é de 52 minutos, tempos de cirurgias de duas horas e 30 minutos e tempo de recuperação médio de uma hora e 40 minutos. A porcentagem média de cirurgias suspensas foi de $50,52 \%$. Grande parte das cirurgias foram eletivas 23922 (60,61\%). Foram observados apenas $2323(5,89 \%)$ óbitos nesse período. Conclui-se que conhecer o desempenho do centro cirúrgico permite o planejamento estratégico para aquisição de novas tecnologias e manutenção adequada de recursos humanos, físicos e materiais garantindo a qualidade e a segurança destes pacientes.

Palavras-chave: Centro Cirúrgico, desempenho, enfermagem

\section{Introdução}

Cirurgias de urgência exige atuação imediata e as eletivas são realizadas em ambulatórios ou Centro Cirúrgico' com diagnóstico estabelecido e agendamento prévio . A caracterização do perfil dos procedimentos cirúrgicos realizados em serviço de saúde assim como de pacientes submetidos aos mesmos é essencial para que o enfermeiro possa identificar as necessidades de atendimento, e realizar um planejamento da assistência que permita um restabelecimento rápido e seguro.

Esse projeto tem a finalidade de nortear a produtividade do Centro Cirúrgico afim de viabilizar o desenvolvimento e implantação de um plano assistência mais adequado quanto aos recursos físicos, materiais e humanos

\section{Resultados e Discussão}

A coleta dos dados foi realizada retrospectivamente das bases de dados armazenadas nos computadores do CC/HC UNICAMP, referente aos anos de 2012-2017. Os dados obtidos foram transferidos para uma planilha e tabulados com o auxílio do programa Microsoft ExceßB e analisados estatisticamente. As variáveis que foram correlacionadas estatisticamente são: faixa etária e sexo, faixa etária e desfecho, local e tipo de cirurgia, sexo e desfecho, desfecho e tipo de anestesia

A amostra do estudo foram as cirurgias realizadas nas salas operatórias de urgência e eletivas.

Tabela 1. As cirurgias totais, realizadas e suspensas ao longo dos últimos cinco anos. Campinas, 2018 ( $n=76216)$.

\begin{tabular}{ccccc}
\hline Ano & Realizadas & Suspensas & Total & $\begin{array}{c}\text { \% de } \\
\text { suspensas }\end{array}$ \\
\hline 2012 & 5469 & 5107 & 10576 & $48,29 \%$ \\
2013 & 8027 & 7846 & 15873 & $49,43 \%$ \\
2014 & 7937 & 8105 & 16042 & $50,52 \%$ \\
2015 & 7827 & 7191 & 15018 & $47,88 \%$ \\
2016 & 7759 & 6348 & 14107 & $45,00 \%$ \\
2017 & 2452 & 2148 & 4600 & $46,70 \%$ \\
\hline Total & 39471 & 36745 & 76216 & $48,20 \%$ \\
\hline
\end{tabular}

Das 870 cirurgias descritas foram evidenciadas as 20 cirurgias mais prevalentes, destacando-se grande parte das cirurgias realizadas foram as eletivas $(61,93 \%)$, com média de idade de 44 anos em pacientes do sexo masculino $(57,83 \%)$ submetidos a correção de fraturas e luxações(6,93\%) e laparotomia exploratória(4,01\%) como procedimentos cirúrgicos mais realizados, tendo como desfecho alta hospitalar(92,66\%).

Observou-se ainda que a prevalência do tipo de anestesia é a geral com 26292 (66,61\%) e nesse caso verifica-se maior desfecho em altas médicas 24119 $(61,11 \%)$, assim como em outros tipos de anestesias. Sedação é o tipo de anestesia de menor prevalência com $579(1,47 \%)$ sendo muito utilizada nas cirurgias de pequeno porte.

\section{Conclusões}

É importante a participação do enfermeiro gestor no processo de avaliação da qualidade e produtividade em um centro cirúrgico detectando e redesenhando atividades que não estão em conformidade, realizando seu monitoramento contínuo e comparando seus achados com os encontrados em busca de melhores práticas.

Conclui-se que a avaliação de desempenho das atividades do centro cirúrgico através de indicadores possibilita uma revisão critica nos principais processos, visando a intervenção nos processos falhos e desenvolvimento de melhorias.

\section{Agradecimentos}

À Direção de Enfermagem do Centro Cirúrgico do Hospital das Clínicas da Unicamp. Este estudo foi apoiado e financiado pelo Programa Institucional de Bolsas de Iniciação Científica (PIBIC) da UNICAMP através do Conselho Nacional de Desenvolvimento Científico e Tecnológico (CNPq).

\footnotetext{
1. Figueiredo NMA, Leite JL, Machado WCA. Centro cirúrgico: Atuação, intervenção e cuidados de Enfermagem. Yendis Editora. 1ª. Edição. São Caetano do Sul-SP, 2009. 156p

2. Sousa CS, Akamine J. Aplicação de indicadores para análise de desempenho do centro cirúrgico. RAS 10 (41), 2008.
} 